\title{
Museus comunitários no Brasil: descolonizando o pensamento museológico
}

\author{
Museos de la comunidade en Brasil: descolonizando el pensamiento \\ museológico
}

Community museums in Brazil: decolonizing museological thinking

\author{
Débora de Souza Simões ${ }^{1}$
}

\begin{abstract}
Resumo
Este artigo tem como objetivo fazer uma análise sobre os museus de comunidade brasileiros, tratando esses como possíveis descolonizadores de um pensamento museológico. Com isso, busca-se fazer uma contextualização histórica sobre a constituição de um fazer museológico colonialista em contraste com a chamada Nova Museologia e os museus de comunidade. Dessa oposição procura-se conectar a Museologia às discussões das Ciências Sociais em três pontos: a crítica à construção da identidade nacional junto aos museus, a desconstrução dessa identidade a partir dos museus de comunidade e, com isso, a descolonização do pensamento museológico, e os pontos de influência da democracia participativa junto à prática da participação social desses novos modelos museológicos.
\end{abstract}

Palavras-Chave: Descolonização; identidade; museus de comunidade; participação; representação.

\section{Resumen}

Este trabajo tiene como objetivo realizar una análisis sobre los museos de la comunidad en Brasil, tratándolos como posibles descolonizadores de un pensamiento museológico. Por lo tanto, buscamos contextualizar históricamente la constituicion del hecho museológico colonial en contraste con la llamada Nueva Museologia y museos comunitarios. Con esta oposición se busca conectar la Museología com las discusiones de Ciencias Sociales en tres puntos: la crítica de la construcción de la identidad nacional junto con los museos, la deconstrucción de esta identidad junto con los museos de la comunidad y, por lo tanto, la descolonización del pensamiento museológico, y los puntos de influencia de la democracia participativa por la práctica de la participación social de estos nuevos modelos museológicos.

Palabras claves: Descolonizació;, identidade; museos de la comunidade; participación; representación.

\begin{abstract}
This paper have as objective make an analisys of the brasilians comunities museums, considering they as decolonizers of a museological thinking. It's was maked a historical contextualization about the constitution of a colonialist museological in contrast to the so-called New Museology and the community museums. This opposition seeks to connect Museology to the discussions of the Social Sciences in three points: the critique of the construction of national identity related to museums, the deconstruction of this identity in community museums, the decolonization of museological thought, and the points of influence of participatory democracy with the practice of social participation in these new museological models.
\end{abstract}

Keywords: Decolonization; identity; community museums; participation; representation.

\footnotetext{
${ }^{1}$ Mestranda em Ciências Sociais; Programa de Pós Graduação em Ciências Sociais/UNESP; Araraquara, São Paulo, Brasil; debora-dss@ @otmail.com. Trabalho apresentado no I Seminário Latino-Americano de Estudos em Cultura - SEMLACult, Foz do Iguaçu/PR, Brasil, 2017.
} 


\section{Introdução}

Este artigo foi primeiramente pensando durante o $8^{\circ}$ Encontro Paulista de Museus ${ }^{2}$; a programação do evento trazia as diversas áreas da museologia, como salvaguarda de acervos, gestão e educação, mas foi durante a apresentação de Mário de Souza Chagas ${ }^{3}$ (Prof. Dr. UNIRIO) dentro do painel denominado "Articulando Museus e Comunidades" que foi possível conectar as discussões da museologia social com as questões tratadas nas ciências sociais; em sua fala, Mário Chagas trazia a crítica relacionada aos museus tradicionais brasileiros, dizendo que esses foram criações de uma etapa histórica colonialista, e questionava: "É possível descolonizar o pensamento museológico?” Para ele o museu não deve ser feito somente para a comunidade, mas com a comunidade, considerava que tais instituições deveriam possuir uma função social como: redução de injustiças e desigualdades sociais, combates aos preconceitos, melhoria da qualidade de vida coletiva, fortalecimento da dignidade e coesão social, utilização do poder da memória a favor das comunidades populares.

A apresentação de Mário Chagas parte de uma vertente recente da museologia, primeiramente conhecida como Nova Museologia, e também reconhecida por outras denominações, como Museologia Social e Sociomuseologia, mas que se referem a uma nova forma de se pensar e trabalhar com os museus, com o pressuposto de que os museus devem possuir uma função social.

Com isso, esse artigo tem como objetivo apresentar a Museologia Social e buscar o debate entre essa e as Ciências Sociais, especificamente na prática museológica desenvolvida a partir dos museus de comunidade, tocando em três pontos: a crítica à construção da identidade nacional junto aos museus, a desconstrução dessa identidade a partir dos museus de comunidade e especificamente, os pontos de influência da democracia participativa junto à prática da participação social desses novos modelos museológicos.

\section{Apresentando a Nova Museologia}

A chamada Nova Museologia abrange diversificadas práticas museológicas que passaram a ser desenvolvidas a partir dos anos setenta do século $\mathrm{XX}$, mas que possuem o

\footnotetext{
${ }^{2}$ Evento que aconteceu no mês de junho de 2016, na cidade de São Paulo.

${ }^{3}$ Disponível em: https://www.youtube.com/watch?v=6BPyh8I2wfl
} 
mesmo fio condutor na história e nos conceitos que abarcam. Ela surge com a demanda por mudanças no modo de se pensar os museus vinda dos próprios museólogos, devido a decadência de público nos museus decorrente de uma rejeição proposital da população aos museus, com o argumento que aqueles espaços não contemplavam a sociedade. Essas primeira discussões possuem raízes francófonas e anglo-saxônicas, mas logo se expandiram para diversos países.

A partir dessa demanda passa-se a pensar a democratização cultural, com o pressuposto de que "[...] o museu tinha sido um instrumento ao serviço das elites sociais e intelectuais, é entendido que a continuação da sua existência deve passar pela sua transformação em instituição ao serviço de todos e utilizada por todos" (DUARTE, 2013, p. 101). Dessa primeira preocupação surgem práticas educativas dentro dos museus, mudanças nas exposições para que ficassem com caráter mais pedagógico; porém, essas primeiras mudanças não foram suficientes para satisfazer o público, principalmente no sentido de representação, pois o acesso aos museus foi democratizado, o acesso àquela cultura material fora democratizada, mas não despertava um sentimento de pertencimento em grande parte da população (DUARTE, 2013).

É dessa problemática que surge a proposta de um ecomuseu (termo cunhado por Hugues de Varin-Bohan e Georges Henri Rivière), que possuía como objetivo pensar a comunidade junto ao seu território, mas um projeto que deveria ser desenvolvido com ampla participação da população local; museu/comunidade/território, essa relação partia de uma vertente ambiental, um museu construído com a população com o objetivo de fazer com que essa pense seu espaço, com soluções a serem dadas aos problemas ambientas e sociais de seu território, assim como de compreender a própria história, cultura e identidade e buscar seu patrimônio nessas relações; sendo o papel dos museólogos de mediadores desse processo. “A população local é, então, não só objeto, mas sujeito da instituição, não somente público, mas agente da ação e da animação" (VARINE-BOHAN, 2000, p. 68-69).

\section{Descolonizando o pensamento museológico brasileiro}

Pensar a descolonização dos museus brasileiros a partir de uma nova concepção de museologia - a Nova Museologia, Museologia Social ou Sociomuseologia -, é romper com o fazer museológico enraizado no país; a palavra descolonização aqui empreendida refere-se à própria ruptura com as práticas museológicas desenvolvidas a partir da implantação dessas 
instituições no Brasil, é romper com as representações que se encontram conectadas à história oficial e à identidade nacional que começou a ser configurada no período imperial.

O primeiro museu brasileiro remonta o momento de chegada da família real no século XIX, o Museu Real (atual Museu Nacional) foi inaugurado em 1818, pertence à uma das instituições culturais implantadas nesse período, abrigava um pequeno acervo de história natural doado pelo rei D. João VI, e somente no final desse mesmo século será caracterizado como um museu de ciências e de caráter nacionalista, segundo Chagas (2015) era voltado para a história da pátria, uma criação ritual e simbólica da nação, assim como também fizeram outras instituições.

A criação do Colégio Pedro II (1837), do Arquivo Nacional (1838), do Instituto Histórico e Geográfico Brasileiro (1838) e a cooptação de artistas plásticos da Academia Imperial de Belas Artes enquadram-se nos esforços de edificação de uma inteligência e de um imaginário sintonizado com os interesses do Estado Imperial (...) (CHAGAS, 2015, p. 44).

Com a Guerra do Paraguai foram criados os museus militares: Museu do Exército (1964) e Museu da Marinha (1868); ainda nesse século outros museus foram inaugurados, o Museu Paraense (1876) e Museu Paulista (1895). A herança que os museus do século XIX deixaram foram os acervos que tentaram contar a memória nacional baseada em heróis, que esqueciam as revoltas, os negros, índios, imigrantes, entre outros. E no final deste mesmo século, museus de ciências também surgirão, esses divergentes das tradições inventadas do nacionalismo (como o nacionalismo romântico financiado por D. Pedro II), porém investidas das teorias raciais, tendo a mestiçagem como identidade do brasileiro.

Em estudo sobre a identidade nacional, Renato Oritz (1994) demonstra que historicamente a identidade brasileira foi resgatada e se viu interpretada por diferentes linhas de pensamento, cada qual marcada por sua época; tais leituras, feitas por uma elite intelectual, atingiram a sociedade no sentido de fazer com que essa refletisse sobre si, se reconhecesse ou não. A busca por uma identidade nacional e sua representação se deu de diferentes formas, constituem um constructo abstrato permeado pelo Estado e mediado por intelectuais; exemplo seria a interpretação racista sobre o brasileiro no final do século XIX e início do XX, que traz a mistura das três raças (branca, negra, e índia) e o meio como causa para o atraso social, econômico e moral, e tem no branqueamento da população a possibilidade de evolução e desenvolvimento de um Estado nacional moderno; a particularidade brasileira é apreendida pelo meio e pela raça, a identidade é marcada pelo mito do brasileiro mestiço. 
Lilia Schwarcz (1993) aponta para a importância das instituições museológicas e institutos históricos para a disseminação dessa visão pessimista em relação ao brasileiro mestiço; os museus de ciências que atuaram no final do século XIX e início do XX - Museu Paraense Emílio Goeldi, Museu Paulista e Museu Nacional - pautavam-se pelos estudos evolucionistas, recebiam naturalistas europeus para o estudo das raças de índios, de “espécies" humanas que acreditavam estarem fadadas ao desaparecimento.

A visão pessimista em relação ao mestiço será superada quando Gilberto Freyre troca a noção de raça pela cultura, o brasileiro como uma fusão cultural, que não são antagônicas, mas diferentes; essa nova perspectiva difundiu-se, esteve presente nos fatos cotidianos e nos eventos nacionais, o brasileiro se reconhece nesse mito, ele é unidade nacional. Interpretação semelhante será posta após o golpe militar de 1964, nesse momento o governo recorre a intelectuais que resgatam a questão racial, mas adicionam a noção de pluralidade, e da mesma forma de Gilberto Freyre, não antagonizam as diferenças, mas sim as harmonizam ressaltando pluralidade como sinônimo de país culturalmente democrático (ORTIZ, 1994).

Para Renato Ortiz esse constructo da identidade nacional, que também é memória nacional, é uma ideologia, é abstrato, está ligado à história e volta-se para o futuro, ela é capaz de unificar as diferenças. Seria antagônica à cultura popular, que é múltipla, está viva na memória coletiva e na vivência, se atualiza nesses dois âmbitos. Os intelectuais da cultura interpretam as culturas populares e servem como mediadores entre o popular e o Estado, esse que se apropria (de acordo com suas necessidades) dos conceitos e os unifica como representação da identidade nacional (ORTIZ, 1994).

Stuart Hall (2011) faz uma leitura semelhante ao fazer referência a Benedict Anderson e considerar a identidade nacional como uma comunidade imaginada, essa que seria característica do próprio tempo moderno, que centraliza e unifica uma sociedade com o Estado, a língua, escola e suas diversas instituições. Mas também existem outras características capazes de dar sentido a uma identificação nacional, e uma delas seria a “[...] narrativa da nação, tal como é contada e recontada nas histórias e nas literaturas nacionais, na mídia e na cultura popular” (HALL, 2011, p. 52). Hall (2011) também aponta que a unificação cultural e a construção de uma representação nacional aconteceram a partir de um processo violento de conquista; "Cada conquista subjugou povos conquistados e suas culturas, costumes, línguas e tradições, e tentou impor uma hegemonia cultural mais unificada" 
(HALL, 2011, p. 60). E para que pudesse acontecer, foi necessário esquecer esse passado violento.

Com isso é possível dizer que a identidade nacional (como as pessoas de uma nação se reconhecem pelo seu particularismo) possui uma íntima relação com a construção da história oficial ou narrativas da nação (característica que marca a identidade), assim como com a memória museológica (que interpretam e representam as identidades e as narrativas); assim, três diferentes problemáticas relacionadas: narrativa da nação (que é história), identidade nacional e memória musealizada. Dessa forma, é possível compreender a dimensão da problemática dos museus tradicionais brasileiros, principalmente os museus históricos.

Considerando a relação entre memória e história, a socióloga Myrian Sepúlveda dos Santos (2005) parte de três pressupostos para caracterizá-la, a primeira de que o passado é construído pelo presente (tanto a história quanto a memória constroem o passado a partir de uma perspectiva do presente) e o presente pelo passado, a segunda que a história é resultado de relações de poder, e a terceira que "[...] tanto a história como a memória são múltiplas e complexas, porque resultado do entrelaçamento de diferentes narrativas, as quais, embora produzidas em diferentes contextos históricos, coexistem no presente" (SANTOS, 2005, p. $37)$.

Assim, os museus ditos tradicionais serviram (e ainda servem) como instituições de veiculação de identidades interpretadas em diferentes momentos (perpassados pelas relações de poder de cada contexto histórico), e todas essas identidades coexistem dentro dos museus, como do indígena romantizado retratado como um personagem do passado, do brasileiro mestiço, da cultura negra inferiorizada, dos negros rememorados somente na cultura popular, entre outras. Porém, como Santos (2005, p. 37) pontuou, tanto a história quanto a memória possuem uma diversidade de narrativas e, com isso, outras interpretações e outras identidades que foram subalternizadas (muitas resgatadas a partir de políticas afirmativas atuais) contestam as identidades forjadas e histórias oficiais. Nesse sentido, as teorias da Nova Museologia vão de encontro com as teorias pós-coloniais, essas que segundo Costa (2006), não possui uma matriz única, mas refere-se a um processo em comum de descentramento teórico, buscar através de uma vertente epistemológica crítica desconstruir o discurso caracterizado como colonial e central.

Os museus comunitários quando implantados fazem um resgate da história e cultura local, quebram com as construções da identidade nacional, regional ou local; em semelhança 
ao que Hall (2011) traz sobre a decadência das identidades nacionais, essas que não deixam de existir, mas junto a elas novas identidades são produzidas, identidades descentradas, aqui não se nega a influência global e nacional nos locais, mas o processo pelo qual os museus de comunidade passam trazem outra forma de se pensar as identidades, àquelas que partem de si para se conhecerem e reconhecerem; conferem a possibilidade de representar histórias e identidades que são refletidas pelos próprios moradores de um determinado território.

Já existem diversos museus de comunidade no mundo e no Brasil, cada qual possui sua especificidade, representam o avesso do denominado museu tradicional, pois como já foi colocado, o objetivo desses museus é fazer com que a própria comunidade passe por um processo reflexivo, que se autorrepresente, que reflita sobre sua história junto ao território em que vive, que compreendam quais os problemas sociais e ambientais de tal espaço (alguns não trazem essa perspectiva ambiental) e criem possibilidades (através do museu) de solucionar problemas locais. Um exemplo de museu de comunidade no Brasil é o Museu da Maré, localizado na Favela da Maré no Rio de Janeiro, inaugurado em 2006, é administrado pela própria comunidade em conjunto com o Ceasm (Centro de Estudos e Ações Solidárias da Maré), esse criado pelos próprios moradores da favela, e com o Ministério da Cultura; esse museu:

trata-se de necessidade vital de um grupo de jovens moradores do complexo de favelas da Maré, que, exercendo o direito à memória e à escrita da história, passam a construir narrativas na primeira pessoa (do singular e do plural) e a escrever uma história pouco conhecida, cuja referência é o ponto de vista de quem nasceu, cresceu e experimentou a vida a partir das suas diferentes comunidades (CHAGAS; ABREU, 2007, p. 132).

Consistiu em um resgate documental dentro e fora da favela; dentro foi realizado um trabalho de história oral e fora de busca pela documentação sobre a favela que "[...] reúne mais de 3.200 itens, é composto por mapas, vídeos, fotografias, recortes de jornais e outros documentos textuais, objetos pessoais, objetos de uso doméstico, alfaias de faina, alfaias religiosas e brinquedos" (CHAGAS; ABREU, 2007, p. 133). Esta documentação refere-se a um complexo de 16 comunidades, da pluralidade de identidades, de histórias, tradições, de tempos diferentes da formação da favela, das migrações, da pobreza, violência, nos medos e problemas sociais. Representa a possibilidade de documentar, escrever a história dessa população e patrimonializar seus bens culturais e, ao mesmo tempo reivindicar políticas públicas. Também tomam o sentido de mostrar a violência e a precariedade do espaço sem estereotipar os moradores, mostrando que são pessoas com história e identidades diversas. 
É possível associar esse processo de reflexão à teoria do reconhecimento de Taylor (1994), no sentido de que as identidades passam por dois processos de reconhecimento, da esfera íntima e da esfera pública, o museu possibilita o conhecimento e reconhecimento histórico e cultural dessa população, ou seja, um reconhecimento do íntimo; o processo de descrição do trabalho realizado no Museu da Maré demonstra como esse atua na quebra de estigmas sobre ser morador de favela, como no depoimento deixado no livro do Museu, uma moradora registrou:

Hoje foi a $1^{\text {a }}$ vez que visitei o museu: estava passando e resolvi entrar. Foi uma das melhores experiências que tive nos últimos anos. Incrível, não!!! É bom saber que temos história, cultura, tradição, etc. Não somos números ou censo de pobreza; somos gente. Que bom que há quem saiba disso e nos faça lembrar porque as vezes esquecemos. Obrigado (CHAGAS; ABREU, 2007, p. 132).

Com isso, possibilita o reconhecimento público, com a demanda de políticas de compensação que visam a cidadania, essa historicamente negada desde as primeiras ocupações do local.

O Museu da Maré consiste apenas em um exemplo, ainda no Rio de Janeiro (talvez pela forte influência da museologia carioca) outros museus foram pensados e concretizados nessa perspectiva, um exemplo é o Museu de Favela (MUF) localizado nas comunidades Pavão-Pavãozinho e Cantagalo, que consiste em uma galeria de artes a céu aberto, pensada e organizada por moradores dessas comunidades que através de grafites nos muros contam a história do local; mais uma vez, um processo reflexivo sobre sua própria história e cultura.

Além desses, outros ainda, como o Museu Vivo de São Bento, Museu do Horto, Ecomuseu Nega Vilma, Ecomuseu Amigo do Rio Joana, Museu das Remoções, Museu do Taquaril, Museu Bispo do Rosário, Ecomuseu da Serra de Ouro Preto, Museu Comunitário Mãe Mirinha de Portão, Ecomuseu do Quarteirão Cultural do Matadouro, Ecomuseu do Cerrado, Ecomuseu da Amazônia, entre outros.

\section{Museus comunitários e a participação social}

A partir do pensamento de Hugues de Varine-Bohan (2014) um museu comunitário deve servir ao desenvolvimento local no âmbito natural, humano e cultural, deve partir da comunidade, um movimento de baixo para cima, mesmo que se utilize de recursos advindos de políticas nacionais ou internacionais, mas a garantia do desenvolvimento deve ser local, porém, para ele as comunidades normalmente não estão preparadas para uma administração dessa amplitude "[...] porque os sistemas existentes de educação pública, previdência social, 
democracia representativa e poder de decisão política não proporcionam a informação necessária e não favorecem a participação popular" (VARINE-BOHAN, 2014, p. 26-27).

Com isso, o museu deveria servir como um meio de comunicação e experimentação para a promoção de participação social na tomada de decisões que beneficiam a própria comunidade (VARINE-BOHAN, 2014). A ideia de destinar aos museus a possibilidade de desenvolvimento comunitário que passa pela necessidade de participação nas decisões possui uma ponte com as teorias desenvolvidas sobre a teoria participativa da democracia, principalmente no que toca a função educativa.

Dentro do debate sobre a participação, Pateman (1992) evidencia que a palavra participação passou a ser recorrentemente utilizada dentro de discursos políticos e pela mídia a partir da década de 60 do século XX, com as reivindicações de movimentos para uma abertura à participação popular nas decisões, em semelhança, quando Varine-Bohan (2014) recorre aos museus comunitários, esses passaram a ser pensados e postos em prática na década de 60 e início de 70 do mesmo século, também decorrentes dos movimentos sociais. Porém, Pateman (1992) aponta que apesar de o termo ter sido difundido, muitos teóricos da sociologia política consideravam tal participação perigosa, com a possibilidade de desembocar em um regime totalitário ou afetar a estabilidade democrática.

A conclusão esboçada (quase sempre por sociólogos políticos transvestidos de teóricos da política) é a de que a visão "clássica" do homem democrático constitui uma ilusão sem fundamento e que um aumento da participação política dos atuais não-participantes poderia abalar a estabilidade do sistema democrático, considerando-se a perspectiva das atitudes políticas (PATEMAN, 1992, p. 11).

A crítica de Pateman (1992) é construída com a análise das teorias contemporâneas da democracia, nessa discussão, considera que para os teóricos modernos a democracia "clássica" não é científica e empírica, a partir disso, ressalta o fato de as atuais discussões estarem vinculadas à revisão teórica feita por Joseph Schumpeter, que também lançou uma nova definição para se compreender a democracia, esta vista como um método político e baseada na realidade, e considerava a competição pelo voto o principal diferencial da democracia, analisando-a como um modelo econômico de política enquanto produtos e eleitores enquanto consumidores; para ele a liberdade civil e a tolerância de opiniões eram necessárias, mas não considerava o sufrágio universal como determinante, e nem mesmo correto o ato de pressionar as lideranças.

Na teoria de democracia de Schumpeter, a participação não tem um papel especial ou central. Tudo o que se pode dizer é que um número suficiente de cidadãos 
participa para manter a máquina eleitoral - os arranjos institucionais - funcionando de modo satisfatório (PATEMAN, 1992, p. 14).

Pateman (1992) traz a influência da teoria de Schumpeter em outros autores, como em Bernard Berelson, Robert Dahl, Giovanni Sartori e Harry Eckstein; suas teorias focaram na relação da estabilidade política e diminuição da participação política; como para Berelson “[...] a participação limitada e a apatia têm uma função positiva no conjunto do sistema ao amortecer o choque das discordâncias, dos ajustes e das mudanças” (PATEMAN, 1992, p. 16). Nesse sentido, Dahl pensa de forma semelhante ao considerar que as classes mais baixas são mais autoritárias e se aumentar a participação dessa parte da população e, se chegarem ao poder, a estabilidade do sistema estará comprometida. Sartori também concorda com a instabilidade do sistema decorrente da maior participação, acredita que poderia levar ao totalitarismo. Para Eckstein a estabilidade do sistema é possível com um elemento autoritário, pois as pessoas necessitam de um líder com caráter autoritário, como uma satisfação psicológica de necessidade.

A crítica de Pateman em relação aos teóricos da contemporaneidade está na forma como descartaram os clássicos baseados na crítica de Shumperter, de que suas teorias não correspondiam à realidade, porém não fazem uma reflexão acerca das mesmas; com isso a própria autora faz um estudo da teoria de Rousseau, John Stuart Mill e G. D. H. Cole. E aqui servirão como ponte para a compreensão da pretensão da museologia social como prática que ajuda e incentiva a participação.

A teoria de Rousseau sobre a participação política dos indivíduos é considerada como a base da democracia participativa, mesmo que não tenha descrito a função da participação dentro de uma sociedade industrial moderna e sim uma cidade de camponeses, para ele a vontade geral deveria prevalecer à individual e a participação provoca um impacto psicológico diante das instituições sociais e políticas, uma função educativa de ensinar a relação entre púbico e o privado, ensinar a cidadania, também possui função de integração e pertencimento. J. S. Mill já pensa a democracia participativa dentro de um sistema político moderno, também ressalta para o caráter educativo da participação política dentro de um âmbito local e, assim como Rousseau, essa prática torna possível pensar a dimensão do público e não somente o privado. G. D. H. Cole amplia a questão da participação, no sentido de que o indivíduo deve participar de decisões em diversas associações que lhe dizem respeito, dentro do bairro, trabalho, deve participar da organização e formulação de leis, os indivíduos e as instituições não devem estar separados (PATEMAN, 1992). 
A proposta de uma museologia que incentiva a participação social nas decisões sobre resolução de problemas internos da própria comunidade segue a mesma linha dos teóricos apresentados, primeiramente porque são museus que possuem como proposta o desenvolvimento da comunidade local, abrangendo a concepção de patrimônio, agora ligado à história, cultura, tradição, território e o meio ambiente; para que funcione faz-se necessário uma reflexão coletiva dos problemas referentes à comunidade, ou seja, pensar o público, os problemas que tocam a todos.

\begin{abstract}
Como o futuro de todos está condicionado a maneira como cada um levantará os problemas coletivos, é essencial que esta problemática não fique no domínio reservado de funcionários delegados pela autoridade central ou de representantes eleitos colocados em situação de notáveis detentores do saber e do poder. O ecomuseu agirá, principalmente, organizando contatos constantes entre grupos de população (associações ou células naturais de vizinhança ou de categorias socioprofissionais) sobre temas como o habitat, a escola, o consumo, as relações interculturais na comunidade, a saúde, o lazer, etc (VARINE-BOHAN, 2000, p. 74).
\end{abstract}

Dessa forma, o museu pode ser visto como uma reunião das associações comunitárias que determinado território possui, que se reúnem para discutir e pensar a dimensão pública, assim, para além de beneficiarem a população local na questão de reconhecimento e identidade cultural, também influencia no trabalho educativo com a participação social.

\title{
Considerações finais
}

A intensão desse artigo foi de contribuir para o debate entre a museologia e as ciências sociais, com a pretensão de demonstrar que ambas as áreas possuem pontos em comum, como com a problemática da identidade na modernidade tardia e a mesma problemática em sua representação nos espaços museológicos. Ambas as áreas se descentralizando, descolonizando, mudando os pontos de referência para compreender essas identidades.

Com isso, a Museologia Social foi colocada para pensar novas formas de se fazer museus e de se compreender as histórias, pessoas e lugares; tais instituições que passaram por uma crise, quando se encontravam em decadência pela falta de público, pelos movimentos que se colocavam contra os museus no final da década de 60 do século XX, como se o tempo de curiosidade desses espaços tivesse passado, e que representava a insatisfação e a falta de representação da população diante dos museus. A partir dessa problemática surgem as práticas de museus comunitários, com a proposta de partirem de baixo para cima, de representar a comunidade no qual está inserida, é um museu de território, pois só faz sentido dentro de sua comunidade; um museu que deve agir de forma orgânica com essa, deve estimular a 
participação para pensar problemas, soluções e a busca pelas histórias e memórias do lugar de onde falam.

Os museus de comunidade também são caracterizados por estarem em constante desenvolvimento, se seu tempo passou, se a comunidade mudou, se os problemas mudaram, este museu passa a ser monumento, pois não está mais em movimento junto de sua comunidade. Portanto, necessita ser repensado.

\section{Referências}

CHAGAS, Mário de Souza. Há uma gota de sangue em cada museu: a ótica museológica de Mário de Andrade. Chapecó, SC: Argos, 2015. 139 p.

CHAGAS, Mário de Souza; ABREU, Regina. Museu da Maré: memórias e narrativas a favor da dignidade social. MUSAS - Revista Brasileira de Museus e Museologia, n. 3, p. 130-152, 2007. ISSN 1807-6149. Rio de Janeiro: Instituto do Patrimônio Histórico e Artístico Nacional, Departamento de Museus e Centros Culturais. Disponível em: http://www.museus.gov.br/wp-content/uploads/2011/01/Musas3.pdf. Acesso em: 21 jul. 2017.

COSTA, Sergio. Pós-colonialismo e différance. In: Dois Atlânticos: teoria social, antiracismo, cosmopolitismo. Belo Horizonte: UFMG, 2006. p. 83-109.

DUARTE, Alice. Nova Museologia: os pontapés de saída de uma abordagem ainda Inovadora. Revista Eletrônica do Programa de Pós-Graduação em Museologia e Patrimônio - PPG-PMUS Unirio: MAST, vol. 6, n. 1, p. 99-117, 2013. ISSN 1984-3917. Disponível em: http://revistamuseologiaepatrimonio.mast.br/index.php/ppgpmus/issue/view/15. Acesso em: 21 jul.2017.

HALL, S. A identidade cultural na pós-modernidade. Rio de Janeiro: DP\&A, 2001. 102 p.

ORTIZ, Renato. Cultura brasileira e identidade nacional. São Paulo: Brasiliense, 1994. 148 p.

PATEMAN, C. Participação e teoria democrática. Rio de Janeiro: Paz e Terra, 1992. 161 p.

SANTOS, Myrian Sepúlveda dos. Canibalismo da Memória: O Negro nos Museus Brasileiros. Revista do IPHAN. Rio de Janeiro, n. 31, p. 37-57, 2005.

SCHWARCZ, Lilia Moritz. O espetáculo das raças: cientistas, instituições e questão racial no Brasil - 1870-1930. São Paulo: Companhia das Letras, 1993. 287 p.

TAYLOR, Charles. Multiculturalismo: examinando a política de reconhecimento. Lisboa: Instituto Piaget, 1994.

VARINE-BOHAN, Hugues de. O ecomuseu. Revista Ciências \& Letras, Porto Alegre, n. 27, p. 61-90, jan./jun. 2000.

VARINE-BOHAN, Hugues de. O museu comunitário como processo continuado. Revista Cadernos do CEOM, Ano 27, n. 41, p. 25-35, dez. 2014. ISSN 2175-0173. Disponível em: https://bell.unochapeco.edu.br/revistas/index.php/rcc/issue/view/168/showToc. Acesso em: 21 jul. 2017. 